\title{
Characterizing the spatial variability of groundwater quality using the entropy theory: II. Case study from Gaza Strip
}

\author{
Y. Mogheir, ${ }^{1,2}$ J. L. M. P. de Lima* ${ }^{3 *}$ and V. P. Singh ${ }^{4}$ \\ ${ }^{1}$ Department of Civil Engineering, Faculty of Science and Technology, Campus 2, University of Coimbra, 3030-290 Coimbra, Portugal \\ ${ }^{2}$ Palestinian Water Authority, Building No. 136/61, League of Arab States St. Tel El Hawa, Gaza, Palestine \\ ${ }^{3}$ Department of Civil Engineering, Institute of Marine Research, Coimbra Interdisciplinary Centre, Faculty of Science and Technology, \\ Campus 2, University of Coimbra, 3030-290 Coimbra, Portugal \\ ${ }^{4}$ Department of Civil and Environmental Engineering, Louisiana State University, Baton Rouge, LA 70803-6405, USA
}

\begin{abstract}
:
This paper, the second in the series, uses the entropy theory to describe the spatial variability of groundwater quality data sets. The application of the entropy theory is illustrated using the chloride observations obtained from a network of groundwater quality monitoring wells in the Gaza Strip, Palestine. The application involves calculating information measures, such as transinformation, the information transfer index and the correlation coefficient. These measures are calculated using a discrete approach, in which contingency tables are used. An exponential decay fitting approach was applied to the discrete models. The analysis shows that transinformation, as a function of distance, can be represented by the exponential decay curve. It also indicates that, for the data used in this study, the transinformation model is superior to the correlation model for characterizing the spatial variability. Copyright (C) 2004 John Wiley \& Sons, Ltd.
\end{abstract}

KEY WORDS correlation; entropy; information; spatial variability; Gaza Strip; Palestine

\section{INTRODUCTION}

Entropy theory (information theory) came to be viewed as a statistical concept at the beginning of the twentieth century. About 50 years later, it found its way into engineering and mathematics, notably through the work of Shannon in communication engineering. Shannon (1948) used entropy as a measure of uncertainty in the mind of someone receiving a message that contains noise. Later, in 1957, Jaynes made use of Shannon's entropy metric to formulate the maximum entropy principle that formed a basis for estimation and inference problems (Golan et al., 1997). In 1972 Amorocho and Esplidora were the first to apply the entropy concept to hydrological modelling (Singh, 1997). Since then, there has been a great variety of entropy applications in hydrology and water resources management (e.g. Rajagopal et al., 1987; Singh and Rajagopal, 1987; Singh, 1998; Harmancioglu et al., 1999). Entropy theory can be used in modelling and decision-making in environmental and water resources, especially in developing countries (Singh, 2000).

Entropy theory also has been applied to assess and evaluate monitoring networks with respect to: water quality (Harmancioglu et al., 1994, Ozkul et al., 2000), rainfall (Krastanovic and Singh, 1992) and groundwater (Bueso et al., 1999; Mogheir and Singh, 2002). Most of these applications involve applying entropy theory to the evaluation, assessment and design of monitoring networks, and they used an analytical approach with a presumed knowledge of the probability distributions of the random variables involved. In the first paper of this series, Mogheir et al. (2004) adopted discrete and analytical approaches using a synthetic

* Correspondence to: J. L. M. P. de Lima, Department of Civil Engineering, Faculty of Science and Technology, Campus 2, University of Coimbra, Portugal. E-mail: plima@dec.uc.pt 
data set, where the data were spatially correlated and fitted the normal distribution function. Under these conditions, it was found that there was a reasonable agreement between discrete and analytical approaches for developing the transinformation model (T model), and it was shown that the T model also could be used instead of the correlation model (C model) to characterize the spatial variability.

In this paper, a different set of data is used. The set of data includes groundwater quality from the Gaza Strip monitoring network (chloride data). For these data, the spatial correlation is low and the normal distribution function does not fit. The objective of this paper is to:

1. use a discrete approach (contingency table) for calculating information measures, such as transinformation (T), information transfer index (ITI) and correlation coefficients.

2. apply an exponential decay fitting approach to the discrete $\mathrm{T}$ model and $\mathrm{C}$ model;

3. use the $\mathrm{T}$ model and $\mathrm{C}$ model to describe the spatial variability of the Gaza Strip data set.

\section{GAZA STRIP GROUNDWATER QUALITY DATA}

The set of data used in the analysis is part of groundwater quality data from the Gaza Strip, Palestine. The data were selected from the groundwater quality data monitored in the middle part of the Gaza Strip. This part of the Gaza Strip is the area with the most serious problems of seawater intrusion. More than 150 wells are used to monitor the groundwater quality in this area. In this study, 26 monitoring wells that monitor chloride were selected. Each well has 52 chloride data measured between 1972 and 1997. Chloride is measured twice per year: in winter and summer. The winter cycle is considered to be taken in April and May whereas the summer cycle is in October and November. The locations of these 26 wells in the middle part of the Gaza Strip are shown in Figure 1. The chloride time-series of the 26 wells are presented in Table I. In the table, $\bar{x}$ is the mean and $S_{x}$ is the standard deviation of the chloride data. The spatial variation of the mean of the chloride time-series in each well is presented in Figure 2. The contour lines were drawn using the kriging technique, which is an option in the Surfer-7 mapping program (Golden Software, 1999). Additionally, the chloride time-series of some of these wells are plotted in Figure 3. The groundwater data in the Gaza Strip (quality and water level) were summarized and presented by the Palestinian Water Authority (PWA, 2000). These data were also used in the modelling of the Gaza Strip aquifer by Metcalf and Eddy (2000).

\section{METHOD}

The method used in this study follows that presented in Mogheir et al. (2004). A contingency table is used for the discrete approach. The discrete models' results were smoothed using the moving average method. For convenience, the base $e$ and the unit nats were used for computing numerical results.

This study differs from Mogheir et al. (2004) mainly in the analytical approach. As the Gaza Strip data, which were used in this study, do not follow the Gaussian distribution function, and their spatial correlations are low, an exponential decay curve is fitted to the discrete models and to the smoothed discrete models (exponential decay fitting approach).

Harmancioglu et al. (1999) investigated the fitting of a semi-exponential curve to the discrete T model. The analysis of the synthetics data (Mogheir et al., 2004) and the shape of the discrete T model, smoothed by the moving average method, of the chloride data set signified that the exponential decay curve could be the best representation of the discrete T model, and could be presented as (e.g. Motulsky, 1999)

$$
T(d)=G \mathrm{e}^{(-K d)}+Q
$$

where the exponential decay curve starts with $T_{0}=G+Q$ at distance $(d)=0$; and the curve decays to reach $Q$ value with a constant rate $K$. The units of $G$ and $Q$ are expressed in the same way as the $T$ unit (nats), 


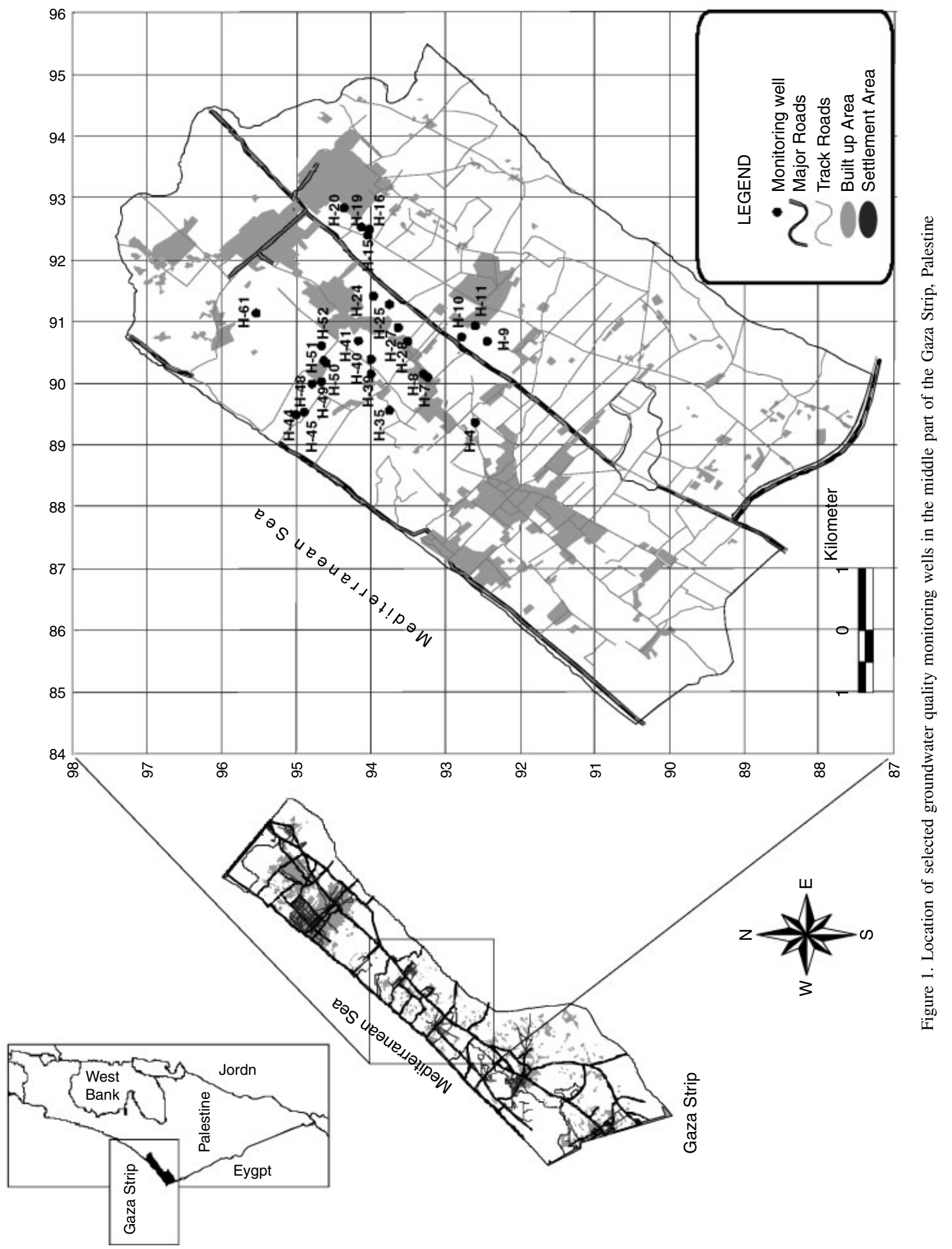




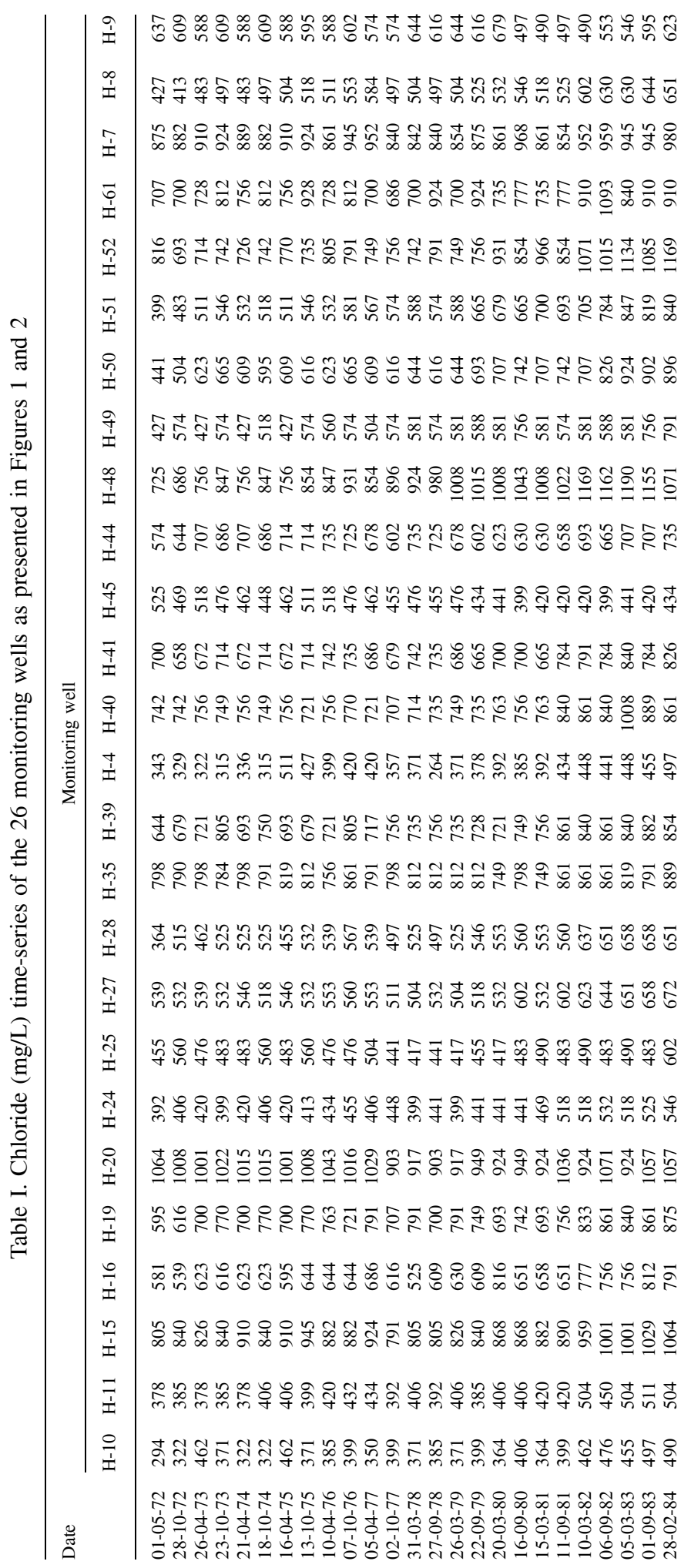




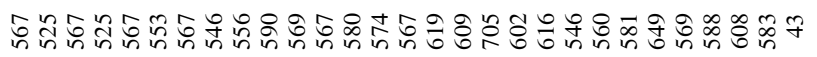

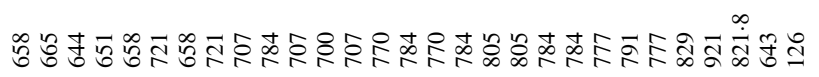

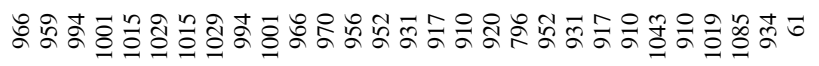

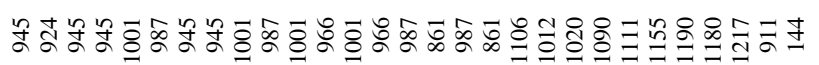

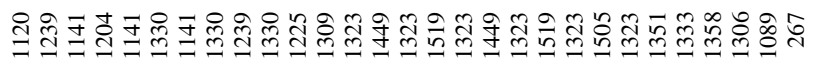

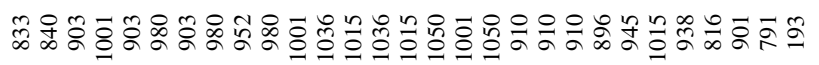

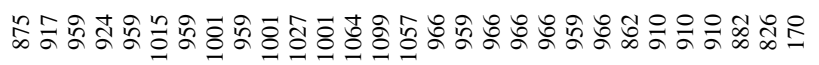

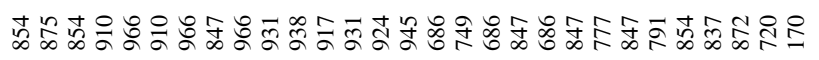

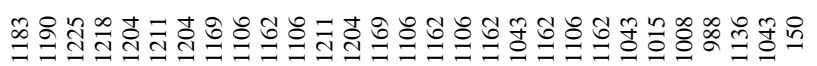

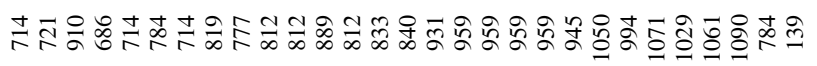

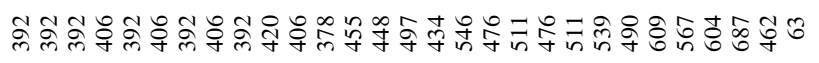

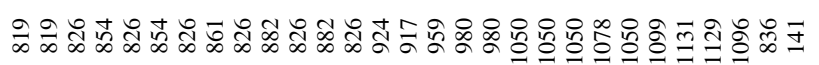

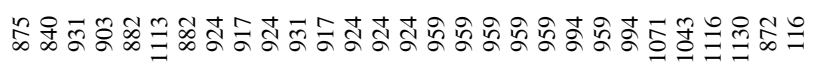

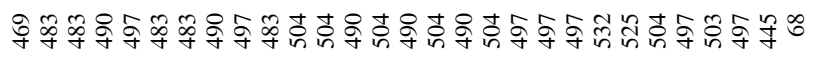

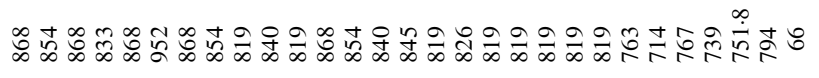
。 \&

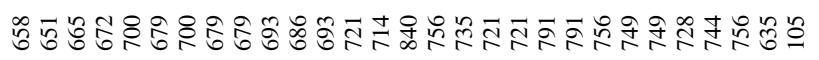

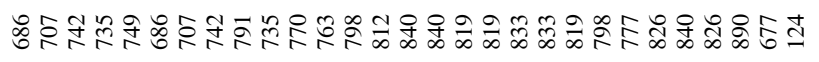

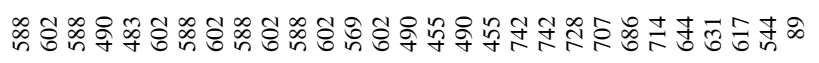

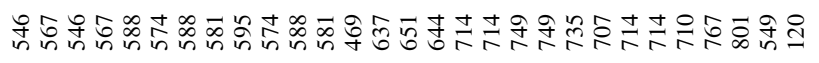

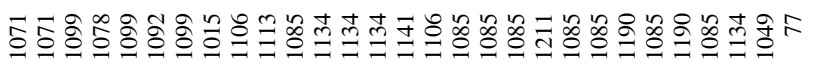

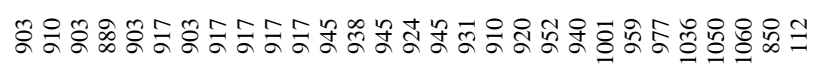

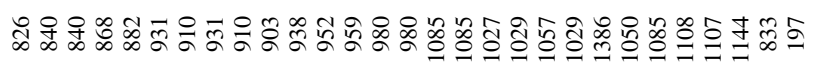

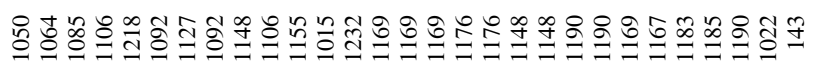
设

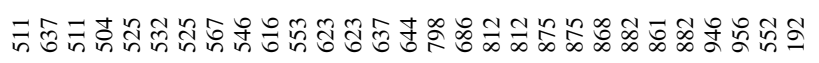

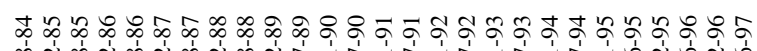

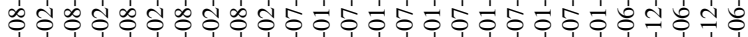

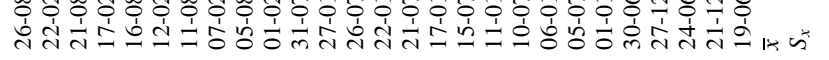




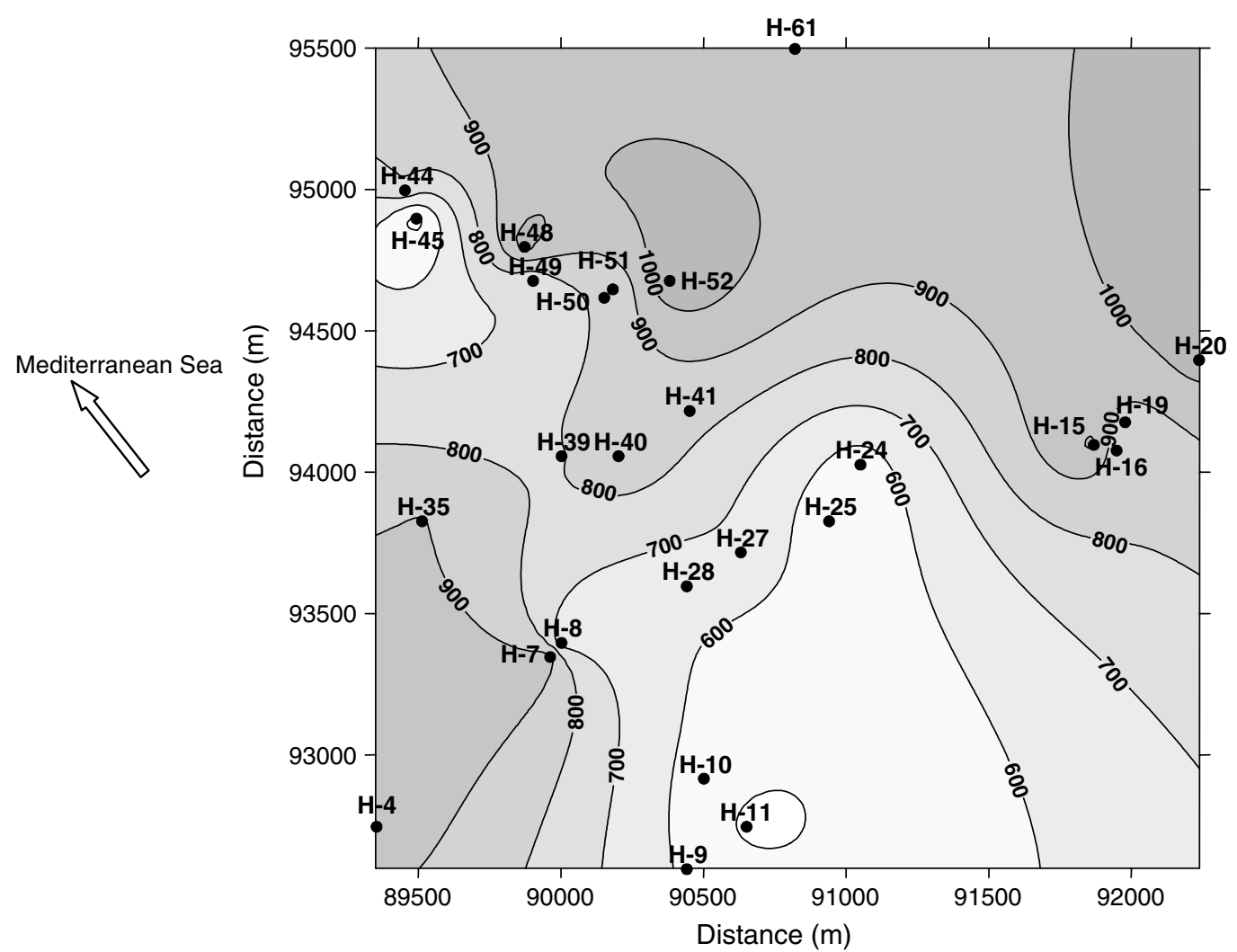

Figure 2. Chloride contour map for the middle part of the Gaza Strip. The average of chloride data $(\mathrm{mg} / \mathrm{L})$ was used in drawing the contour map

whereas $K$ is expressed in the inverse unit used by $d(1 / \mathrm{m})$. Note that Equation (1) was also used to represent the analytical lognormal T, ITI and correlation models.

The fitting of the exponential decay curve to the discrete models was performed using the least-square fitting procedure with the GRAPHPAD PRISM statistical software (Motulsky, 1999). The coefficient of determination was used to quantify the goodness of fit between the exponential decay curve and discrete models. The coefficient of determination $\left(R^{2}\right)$ was computed as (e.g. Motulsky, 1999)

$$
R^{2}=1 \cdot 0-\frac{S S_{\text {reg }}}{S S_{\text {tot }}}
$$

where $S S_{\text {reg }}$ is the sum of the squares of the residuals between the discrete model and the best-fit exponential decay curve, and $S S_{\text {tot }}$ is the sum of the squares of the residuals between the discrete model and the horizontal line through the mean.

As in Mogheir et al. (2004), the T model and C model were compared to characterize the spatial variability of the Gaza Strip data set.

\section{COMPARISON OF DISCRETE AND EXPONETIAL DECAY FITTING APPROACHES}

\section{Correlation model (C model)}

The discrete $\mathrm{C}$ model is obtained by computing the correlation values using the discrete approach and the distance between wells. The discrete C-Model data is smoothed by using the moving average method 

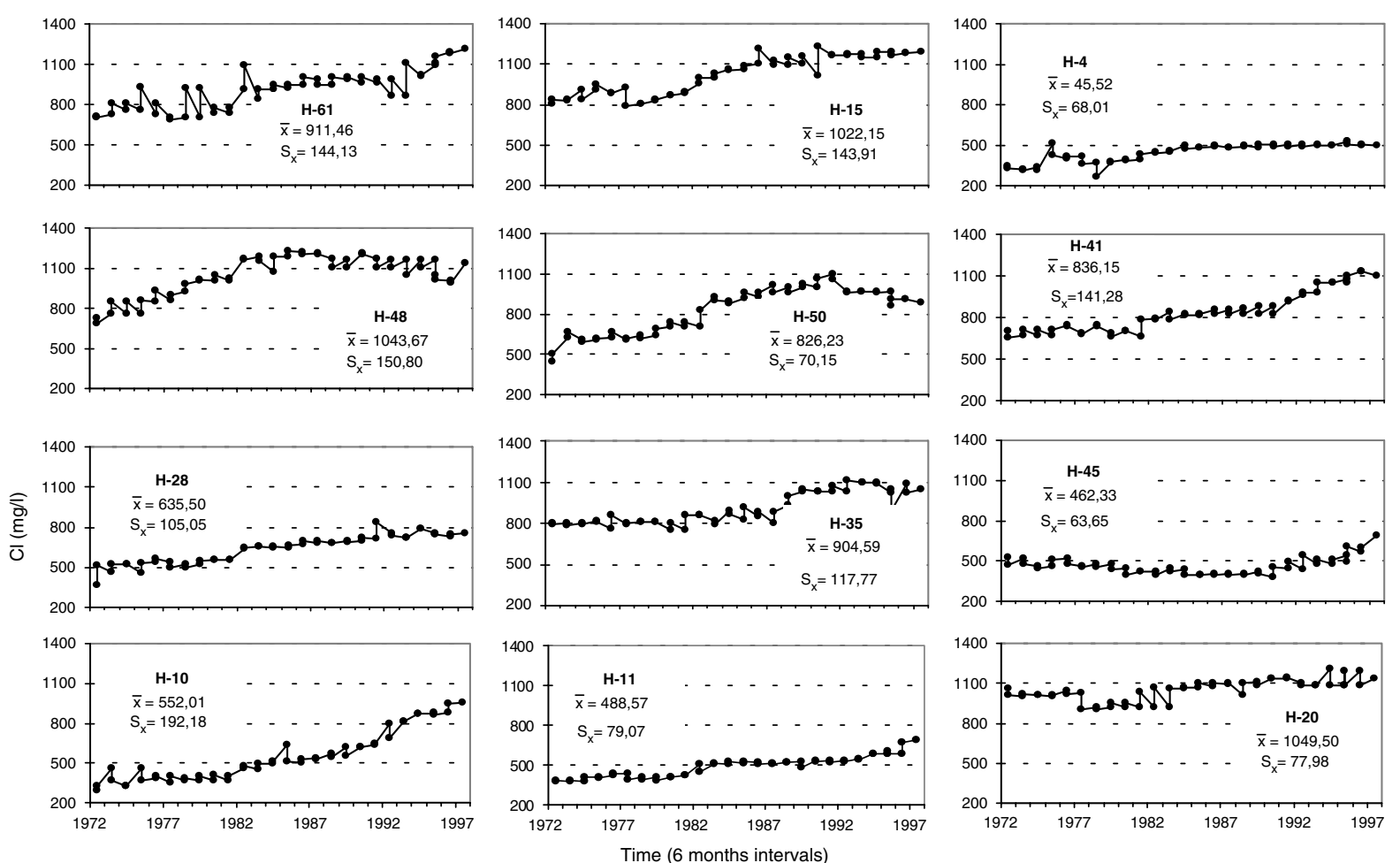

Figure 3. Chloride time-series of 12 monitoring wells (H-10, H-11, H-20, H-28, H-35, H-45, H-48, H-50, H-41, H-61, H-15 and H-4) for the period winter 1972 to summer 1997, used in the analyses. In the graph $\bar{x}$ is the mean of the chloride time-series and $S_{x}$ is the standard deviation

$\left(\mathrm{DCM}_{\mathrm{MA}}\right)$. The exponential decay fitting approach is applied to the discrete $\mathrm{C}$ model and $\mathrm{DCM}_{\mathrm{MA}}$. A summary of the best-fit equations of the exponential decay curve to the discrete T, lognormal T, ITI, correlation models and $R^{2}$ values for each model is presented in Table II.

The discrete $\mathrm{C}$ model $(\mathrm{DCM})$, the $\mathrm{C}$ model smoothed by the moving average method $\left(\mathrm{DCM}_{\mathrm{MA}}\right)$ and the exponential decay of the discrete $\mathrm{C}$ model $\left(\mathrm{DCM}_{\mathrm{ED}}\right)$ are plotted in Figure 4. This figure and Table II show that $\mathrm{DCM}_{\mathrm{ED}}$ does not fit the discrete $\mathrm{C}$ model well, as $R^{2}=0.07$, which is very low. The coefficient $R^{2}$ is increased by applying the exponential decay fitting approach to the $\mathrm{DCM}_{\mathrm{MA}}\left(R^{2}=0 \cdot 22\right)$. Nevertheless, for both the $\mathrm{DCM}_{\mathrm{MA}}$ and discrete $\mathrm{C}$ models the coefficient $R^{2}$ is quite small. Therefore, the exponential decay curve, which was selected to present the discrete $\mathrm{C}$ model, does not infer the spatial variability of the chloride data adequately.

Table II. Fitting discrete models with the exponential decay curve applied to the Gaza Strip data

\begin{tabular}{llc}
\hline Model type & \multicolumn{1}{c}{ Fitting equation } & $R^{2}$ \\
\hline Discrete C model & $r(d)=0.43 \mathrm{e}^{(-0.0033 d)}+0.53$ & 0.07 \\
Discrete T model & $T(d)=0.29 \mathrm{e}^{(-0.0087 d)}+0.90$ & 0.33 \\
Lognormal discrete T model & $T(d)=0.90 \mathrm{e}^{(-0.0102 d)}+0.59$ & 0.43 \\
Discrete ITI model & $\mathrm{ITI}(d)=0.39 \mathrm{e}^{(-0.0359 d)}+0.61$ & 0.57 \\
\hline
\end{tabular}




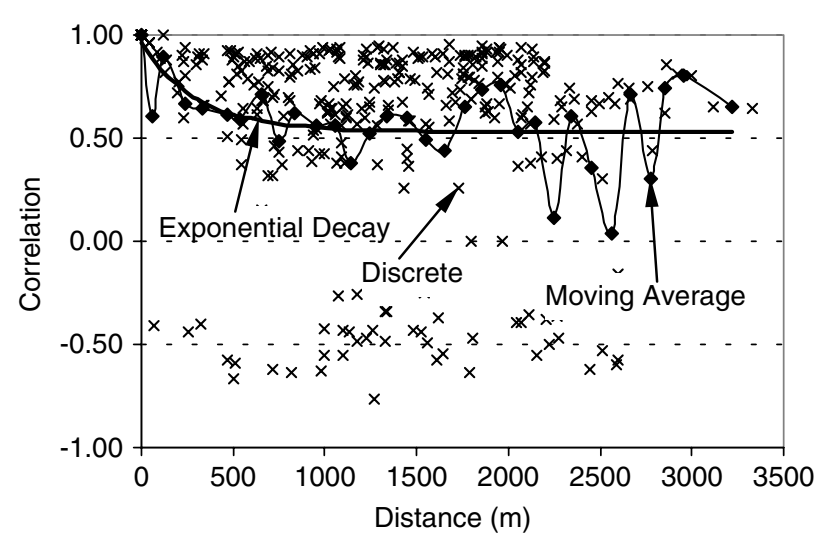

Figure 4. Correlation models for the groundwater quality monitoring network in the middle part of Gaza Strip (chloride)

\section{Transinformation model (T model)}

The discrete $\mathrm{T}$ model was obtained in the same way, by computing the $\mathrm{T}$ values using the discrete approach and the distance between wells. The discrete $\mathrm{T}$ model data were smoothed using the moving average method $\left(\mathrm{DTM}_{\mathrm{MA}}\right)$. The exponential decay fitting approach is applied to the discrete T model and DTM MA. For the discrete T model, the $R^{2}$ coefficient is $0 \cdot 33$, which is smaller than that for $\mathrm{DTM}_{\mathrm{MA}}\left(R^{2}=0 \cdot 71\right)$. This indicates that the exponential decay curve fits the $\mathrm{DTM}_{\mathrm{MA}}$ much better than does the discrete $\mathrm{T}$ model. The discrete $\mathrm{T}$ model, the DTM $\mathrm{MA}_{\mathrm{MA}}$ and exponential decay of the discrete $\mathrm{T}$ model $\left(\mathrm{DTM}_{\mathrm{ED}}\right)$ are plotted in Figure 5.

\section{T-model using logarithmic chloride data}

As the normal distribution did not fit the chloride data well, the lognormal distribution was assumed. The chloride logarithmic data from the Gaza Strip monitoring wells are used to compare the discrete and exponential decay fitting approaches in obtaining the $\mathrm{T}$ values. The logarithmically transformed chloride data are used to check the fitting of the normal function by constructing the histogram and plotting the probability diagram. The chi-square test was used to assess the adjustment of the lognormal distribution to the empirical data.

After fitting the lognormal function of the chloride data from the Gaza monitoring wells, the lognormal discrete T model (lognormal DTM) is obtained by computing the $\mathrm{T}$ values of the logarithm of the chloride data, using the discrete approach and the distance between wells. The lognormal discrete $\mathrm{T}$ model is smoothed

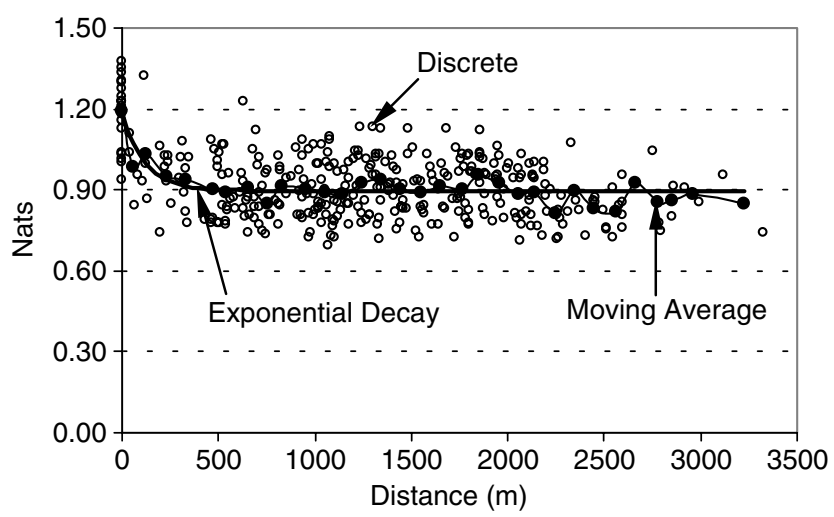

Figure 5. Transinformation models for the groundwater quality monitoring wells in the middle part of Gaza Strip (chloride) 
using the moving average method (lognormal $\mathrm{DTM}_{\mathrm{MA}}$ ). The exponential decay fitting approach is applied to the lognormal discrete $\mathrm{T}$ model and to the lognormal DTM $\mathrm{MA}_{\mathrm{MA}}$. Figure 6 illustrates the lognormal discrete $\mathrm{T}$ model, the lognormal $\mathrm{DTM}_{\mathrm{MA}}$ and the exponential decay of the lognormal discrete T model (lognormal $\mathrm{DTM}_{\mathrm{ED}}$ ). From Figure 6, it can be seen that, for the lognormal DTM $\mathrm{MA}, R^{2}$ is 0.68 which is greater than the $R^{2}$ value obtained by the lognormal discrete T model $\left(R^{2}=0.43\right)$. As for all the T models, the exponential decay curve fits better to the DTM $\mathrm{DA}_{\mathrm{MA}}$ than that to the discrete T model. The lognormal DTM $\mathrm{ED}_{\mathrm{ED}}$ is compared with the DTM $\mathrm{ED}_{\mathrm{ED}}$. As shown in Figure 6, the minimum value of the transinformation in the lognormal DTM $\mathrm{ED}_{\mathrm{ED}}$ is 0.3 nats less than that found in the $\mathrm{DTM}_{\mathrm{ED}}$. Additionally, the initial value of the transinformation in the lognormal DTM $\mathrm{ED}_{\mathrm{E}}$ is 0.3 nats greater than that in the DTM $\mathrm{ED}$. This indicates that the T model is sensitive to the type of distribution of the data, whether its normal or lognormal.

\section{CHARACTERIZATION OF SPATIAL VARIABILITY}

When comparing the correlation model ( $\mathrm{C}$ model) and the transinformation model (T model), to characterize the spatial variability of the chloride data, Figure 4 shows that the discrete $\mathrm{C}$ model is highly scattered and the exponential decay curve does not fit to the discrete $\mathrm{C}$ model well. This is also found where $R^{2}=0.07$ and 0.22 for the discrete $\mathrm{C}$ model and $\mathrm{DCM}_{\mathrm{MA}}$, respectively. On the other hand, Figure 5 shows that the exponential decay curve fits to the $\mathrm{DTM}_{\mathrm{MA}}$ better than it does to the discrete T model, as $R^{2}=0.33$ and 0.71 for the discrete $\mathrm{T}$ model and DTM $\mathrm{MA}$, respectively. Furthermore, the $R^{2}$ values are greater if the logarithmically transformed chloride data are used.

As the ITI and correlation models have the same range from 0 to 1, they are compared in Figure 7, which demonstrates that there is less scatter in the discrete ITI model, which is smoothed by the moving average method (DITIM $\mathrm{MA}_{\mathrm{A}}$ ), than there is in the DCM $\mathrm{DA}_{\mathrm{MA}}$. The $R^{2}$ value for DITIM $\mathrm{MA}_{\mathrm{A}}$ is $0 \cdot 79$, which is greater than that for the $\operatorname{DCM}_{\mathrm{MA}}\left(R^{2}=0 \cdot 22\right)$. These values suggest that the exponential decay curve is representing the ITI model much better than it represents the $\mathrm{C}$ model. As a result, it can be inferred from Figures 5-7 that the $\mathrm{T}$ model and ITI model represent the dependency between wells better than the discrete $\mathrm{C}$ model.

In the above analysis, the dependency is described by an exponential decay model, which is relevant to the $\mathrm{T}$ model because the $\mathrm{T}$ value is maximized at a distance equal to zero. The maximum $\mathrm{T}$ value equals the average of the marginal entropies of the 26 wells. There is a sharp drop in the $\mathrm{T}$ value when the distance is around $500 \mathrm{~m}$. With a further increase in the distance, $\mathrm{T}$ becomes essentially constant. Therefore, what is significant for the spatial assessment and redesign of monitoring wells is selecting the distance at which $\mathrm{T}$ has a minimum steady value. The prescribed $500 \mathrm{~m}$ value may be adopted as the recommended distance between wells. This distance can be utilized in the assessment stage under the following conditions.

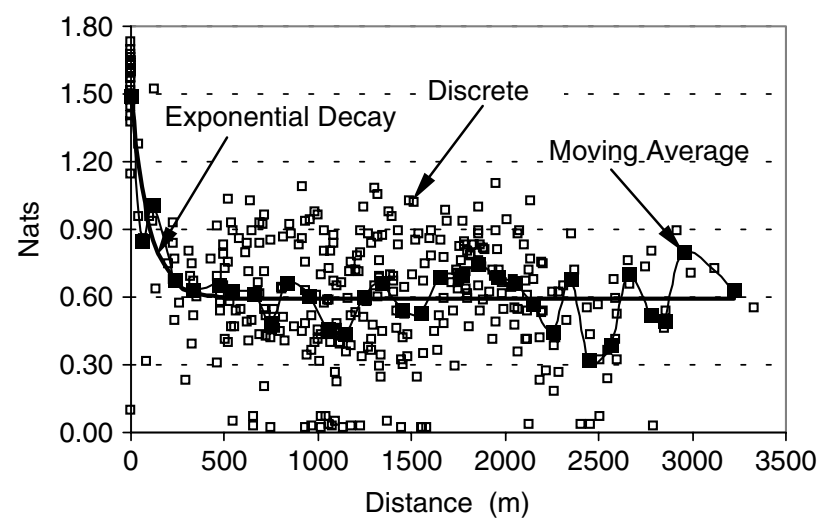

Figure 6. Lognormal $\mathrm{T}$ models applied to the chloride data. The lognormal probability distribution was used in the analyses 


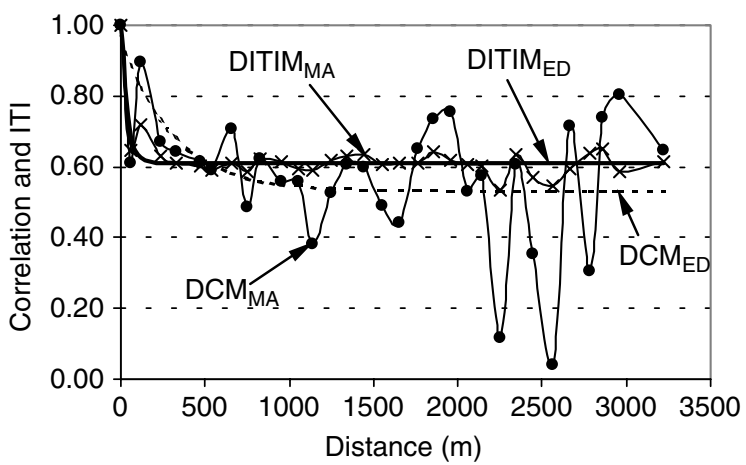

Figure 7. Comparison between $\mathrm{C}$ model and ITI model using the discrete and exponential fitting approaches, for the chloride data. In the figure: $\mathrm{DCM}_{\mathrm{MA}}=$ smoothed discrete $\mathrm{C}$ model by the moving average method; DITIM $\mathrm{MA}_{\mathrm{A}}=$ smoothed discrete ITI model by the moving average method; $\mathrm{DCM}_{\mathrm{ED}}=$ exponential decay of the discrete $\mathrm{C}$ model; DITIM $\mathrm{ED}=$ exponential decay of the discrete ITI model

1. If the distances between wells are less than the recommended distance, then there is available transinformation (redundant information) between wells.

2. If the distances between the existing wells are greater than the recommended distance, then the transformation between wells is less than the minimum transinformation value (not enough information).

3. The adequate information that can be available between wells is found only where the distances between wells equal the recommended distance and the transinformation is minimum.

These arguments afford efficient criteria to assess and redesign the existing wells according to that recommended distance and minimum redundant information between wells. Consequently, the number of wells can be extended or reduced.

It is also useful for redesigning groundwater quality monitoring networks, and developing an analytical equation to relate $\mathrm{T}$ and distance. This equation can form an exponential decay curve, as in the synthetic data (Mogheir et al., 2004) and the chloride data example, or any other type of curve. The monitoring network redesign procedure also might need to look at the variations of the value of $\mathrm{T}$ and the shape of the $\mathrm{T}$ model by changing the number of wells and the size of the time-series used for constructing the T model.

\section{CONCLUSIONS}

This article has presented a comparison between the discrete and exponential decay fitting approaches, using a groundwater quality data set from the Gaza Strip (chloride data). The following conclusions can be drawn.

1. The exponential decay fitting approach shows that the exponential decay curve does not fit to the discrete correlation model well.

2. The exponential decay curve fits to the discrete $\mathrm{T}$ model, the lognormal discrete $\mathrm{T}$ model and the discrete ITI model much better than does to the discrete correlation model.

3. The characteristics of the exponential decay of the lognormal discrete $\mathrm{T}$ model, such as the minimum $\mathrm{T}$ and initial $\mathrm{T}$, differ from those of the exponential decay of the discrete $\mathrm{T}$ model.

4. The discrete $\mathrm{T}$ and ITI models are superior to the discrete correlation model for characterizing the spatial variability by means of an exponential decay model.

The exponential decay $\mathrm{T}$ model can be used to evaluate a groundwater monitoring network. Furthermore, the $\mathrm{T}$ model can be used to redesign the monitoring network by either increasing or decreasing the number of wells. The assessment and redesigning of a groundwater quality monitoring network, using the sensitivity 
of the T model to the number of monitoring wells and the size of time-series, are part of an ongoing study by the first author.

\section{ACKNOWLEDGEMENTS}

The authors gratefully thank the Foundation for Science and Technology of the Portuguese Ministry of Science and Technology for sponsoring the fellowship (Reference: SFRH/BD/6089/2001). The fellowship was provided for the first author's PhD programme entitled 'Quantification of Information for Groundwater Quality Networks'. The programme is being undertaken at the Department of Civil Engineering, Faculty of Science and Technology, University of Coimbra, Coimbra, Portugal.

\section{APPENDIX}

List of symbols and abbreviations

Symbols.

$G \quad$ the value of transinformation where distance equals 0 deducted from $Q$ (NATS)

$K \quad$ the transinformation decay rate $(1 / \mathrm{m})$

$\operatorname{ITI}(d)$ information transfer index as a function of distance (NATS)

$Q \quad$ the end value of transinformation at which the distance is maximum (NATS)

$R^{2} \quad$ coefficient of determination

$r(d)$ correlation as a function of distance.

$S S_{\text {reg }}$ sum of the squares of the residuals between the discrete model and the best fit curve (analytical model)

$S S_{\text {tot }}$ sum of squares of the residuals between the discrete model and the horizontal line through the mean

$S_{\mathrm{x}} \quad$ sample standard deviation of variable $x$

$T(d)$ transinformation as a function of distance (NATS)

$\bar{x} \quad$ sample mean of variable $x$

\section{Abbreviations.}

$\begin{array}{ll}\text { C model } & \text { correlation model } \\ \text { DCM } & \text { discrete correlation model } \\ \text { DCM }_{\mathrm{ED}} & \text { exponential decay of the discrete C model } \\ \text { DCM }_{\mathrm{MA}} & \text { smoothed discrete correlation model by the moving average method } \\ \text { DITIM } & \text { discrete ITI model } \\ \text { DITIM }_{\mathrm{ED}} & \text { exponential decay of the discrete ITI model } \\ \text { DITIM } & \text { smoothed discrete ITI model by moving average method. } \\ \text { DTM } & \text { discrete transinformation model } \\ \text { DTM } & \text { exponential decay of transinformation model } \\ \text { DTM } & \text { smoothed discrete transinformation model by the moving average method } \\ \text { ITI model } & \text { information transfer index model } \\ \text { Lognormal DTM } & \text { exponential decay of lognormal discrete transinformation model } \\ \text { Lognormal DTM } & \text { lognormal discrete transinformation model } \\ \text { Lognormal DTM } & \text { smoothed lognormal discrete transinformation model by the moving average method } \\ \text { T model } & \text { transinformation model }\end{array}$

\section{REFERENCES}

Amorocho J, Esplidora B. 1973. Entropy in the assessment of uncertainty of hydrologic systems and models. Water Resources Research 9: $1522-1551$. 
Bueso MC, Angulo JM, Cruz-Sanjulian J, Carcia-Arostegui JL. 1999. Optimal spatial sampling design in a multivariate framework. Mathematical Geology 31(5): 507-525.

Golan A, Judge G, Miller D. 1997. Maximum Entropy Econometrics, Robust Estimation With Limited Data. Wiley: Chichester; 307 pp. Golden Software. 1999. Surfer Version 7, Surface Mapping System. Golden Software: Colorado, USA. www.goldensoftware.com.

Harmancioglu NB, Alpaslan N, Singh VP. 1994. Assessment of the entropy principle as applied to water monitoring network design. In Stochastic and Statistical Methods in Hydrology and Environmental Engineering, Vol. 3, Hipel KW, Mcleod AI, Panu US, Singh VP (eds). Kluwer: Dordrecht: $135-148$.

Harmancioglu NB, Fistikoglu O, Ozkul SD, Singh VP, Alpaslan MN. 1999. Water Quality Monitoring Network Design. Kluwer: Boston; 299 pp.

Jaynes ET. 1957. Information theory and statistical mechanics I. Physics Revision 106: 620-650.

Krastanovic PF, Singh VP. 1992. Evaluation of rainfall networks using entropy II. Water Resources Management 6: $295-314$.

Metcalf E, Eddy E. 2000. Coastal Aquifer Management Program, Final Report: Modelling of Gaza Strip Aquifer. The programme is funded by US Agency for International Development (USAID) and owned by the Palestinian Water Authority (PWA): Gaza.

Mogheir Y, Singh VP. 2002. Application of information theory to groundwater quality monitoring networks. Water Resources Management 16(1): $37-49$.

Mogheir Y, de Lima JLMP, Singh VP. 2004. Characterizing the spatial variability of groundwater quality using the entropy theory: I. Synthetic data. Hydrological Processes (in press).

Motulsky HJ. 1999. Analysing Data with GraphPad Prism. GraphPad Software: San Diego. www.graphpad.com

Ozkul S, Harmancioglu NB, Singh VP. 2000. Entropy-based assessment of water quality monitoring networks. Journal of Hydrologic Engineering, American Society of Civil Engineers 5(1): 90-100.

PWA. 2000. Summary of the Palestinian Hydrologic Data, Volume 2: Gaza. Technical and Financial support from US Agency for International Development (USAID) and US Geology Survey, Palestinian Water Authority: Gaza.

Rajagopal Ak, Teitler S, Singh VP. 1987. Some new perspectives on maximum entropy techniques in water resources research. In Hydrologic Frequency Modelling, Singh VP (ed.). Reidel: Dordrecht; 247-366.

Shannon CE. 1998. A mathematical theory of communication. Bell System Technical Journal 27: $379-423$.

Singh VP. 1997. The use of entropy in hydrology and water resources. Hydrological Processes 11: 587-626.

Singh VP. 1998. Entropy-based Parameter Estimation in Hydrology. Kluwer: Boston.

Singh VP. 2000. The entropy theory as a tool for modelling and decision-making in environmental and water resources. Water SA 1: $1-11$.

Singh VP, Rajagopal AK. 1987. Some recent advances in application of the principle of maximum entropy (POME). International Association of Hydrological Sciences Publication: 164: 353-364. 